\title{
Exploring Hotel Employee's Work Stress by Individual Characteristics
}

\author{
Chieh-Heng Ko \\ Department of Hospitality Management, College of Tourism and Hospitality, Da-Yeh University, Taiwan \\ Email: chko@mail.dyu.edu.tw
}

How to cite this paper: Ko, C.-H. (2020) Exploring Hotel Employee's Work Stress by Individual Characteristics. Open Access Library Journal, 7: e6023.

https://doi.org/10.4236/oalib.1106023

Received: December 23, 2019

Accepted: January 13, 2020

Published: January 16, 2020

Copyright () 2020 by author(s) and Open Access Library Inc.

This work is licensed under the Creative Commons Attribution International License (CC BY 4.0).

http://creativecommons.org/licenses/by/4.0/

\section{(c) (i) Open Access}

\begin{abstract}
This paper explores the common work stress in a sample of Taiwanese managers and employees. It investigates the differences and frequency of work stress by individual characteristics such as job level, gender and marital status. The researcher distributed a self-administered questionnaire to a sample of $N=140$ managers and $N=400$ front-line employees at 20 Taiwanese five-star hotels. The results revealed that role conflict, role ambiguity and workload were the most common stressors for managers and employees. In addition, hotel managers experienced significantly more stress than front-line employees did. Female employees indicated significantly more stress than did their male counterparts. Some implications for practice are discussed such as recruiting employees who can function optimally even in stressful situations, which would help lower costs.
\end{abstract}

\section{Subject Areas}

Socioeconomics

\section{Keywords}

Work Stress, Front-Line Employees, Hotel Industry

\section{Introduction}

The hospitality industry is highly stressful, as it involves hard labor, strict deadlines, unexpected interactions with guests, long working hours, night and evening shifts, repetitive work in frequent rotations, work overload, antisocial working hours and interaction with demanding customers [1]. Furthermore, hospitality employees may not be capable of handling such stressors [2].

Based on the above-mentioned affirmations, front-line employees constantly interact with guests; the real-time nature of service delivery subject workers in 
this environment not only to the pressure of ensuring prompt response but also to several competing, often contradictory or conflicting demands and expectations for various services. This can result in health-related issues as well as absenteeism and labor turnover.

Moreover, stress in the workplace has been well established as leading to higher rates of ill health. Jobs represent a central part of everyday life for most people. The impact of work on the lives and welfare of people during both working hours and non-working hours has grown increasingly significant over time. As a result, job stress is on the rise, leading to greater healthcare costs, a higher percentage of absenteeism and turnover and inefficient performance [3].

Previous studies focused on the outcomes of job stress, although not on particular personal characteristics, such as gender, marital status and job type. It is important to note that job stress is a subjective cognition [4]. For example, different people (e.g., hotel employees) working in the same task environment may experience different levels of job stress. This may be because people with different personal characteristics tend to perceive different levels of job stress under the same working conditions. Most studies on job stress have been developed and empirically tested in Western industrialized societies, although the prevalence of this phenomenon in developing countries has not been studied [3].

Addressing and reducing stress is pertinent and cost-effective for employers, as some studies of work stress (WS) among hotel employees have shown [5]. However, these studies were limited to Europe.

It is likely that employers in Taiwan are facing similar challenges. Therefore, this research aims to determine the recurrent stressors for the Taiwanese hospitality workforce based on individual characteristics such as gender, job level and marital status, thus providing better insight into the WS of Taiwanese hotel employees at present. The specific objectives of this research are as follows:

Explore the most common work stressors experienced by Taiwanese hotel employees;

Determine the differences of work stressors by job level (i.e., managers vs. frontline employees);

Examine the differences of work stressors by gender; and

Determine the differences of work stressors by marital status.

The literature contains multiple categories based on various personal characteristics. The current study focuses primarily on personal demographics, to investigate their effect on perceived job stress. Based on the study findings, the implications for practice are discussed.

\section{Literature Review}

\subsection{Job Stress}

Stress refers to one's response to threats arising from one's job [6]; it also refers to situations that are detrimental to the well-being of individuals as they fail to cope with the demands of their environment [7]. In particular, WS is the inabil- 
ity to cope with the pressures in a job, because of a poor fit between one's abilities and one's work requirements and conditions [8]. Apparently, the main components of the work stress process are potential sources of stress, factors of individual differences (moderators/mediators) and consequences of stress [9].

WS has become a serious health issue in modern society [9], as it is increasingly prevalent in all jobs unlike decades earlier [7].

\subsection{Causes of Workplace Stress}

The literature reported various stressors. According to Antoniou, Polychroni, and Vlachakis [10], stressors can be categorized either as exogenous (i.e., unfavorable occupational conditions, excessive workload, lack of collaboration, etc.) or as endogenous pressures (i.e., individual personality characteristics, etc.).

In addition, the stress literature revealed other stressors such as role conflict, role ambiguity, workload and interpersonal conflict [11]. Role conflict involves the simultaneous occurrence of two or more sets of conflicting pressures. Role ambiguity is the uncertainty regarding others' expectations for an employee's performance, the actions needed to meet those expectations and the overall consequences of one's job behavior [12]. Workload refers to the degree to which one's job requires one to work hard or fast, the quantity of work required and the amount of time needed to complete the work [13]. Interpersonal conflict includes, for example, arguing with, being yelled at by, or being disrespected by others at work [13].

\subsection{Antecedents of WS}

In the literature, work stressors such as role conflict, role ambiguity and workload have been found to be directly and positively related to WS [14].

In particular, role conflict and role ambiguity were the two major components of job-related stress [15]. According to a meta-analytic review of WS studies, role involvement at work, social support at work, work characteristics and employee personality were the antecedents of job stress [16].

\subsection{Role Conflict}

Role conflict arises from multiple roles due to an incompatibility between different functions and responsibilities of the roles as well as psychological conflict, for instance, when an employee's job-related role interferes with his/her family or personal life [17]. According to Greenberger and O'Neil [18], involvement in various roles led to role strains, role conflicts and a negative impact on mental and physical health. Some researchers have also argued that increased role obligations demanding time and participation may result in various forms of psychological conflict if each role cannot be adequately fulfilled [19].

Discrepancies in the impact on multiple roles have been noted in recent literature. According to the "enhancement expansionist theory", eminent researchers have empirically shown that role accumulation can benefit men and women 
in terms of buffering, social support, opportunities for success and increasing sources of reference [20]. In addition, empirical evidence has also shown a common consensus that psychological stress is a result of numerous roles [21].

\subsection{Role Ambiguity}

"Role ambiguity is the degree of certainty the employee has about what his or her functions and responsibilities are" [17]. According to conventional theories, any role in an organization chart should have a specified set of tasks or responsibilities, and role ambiguity indicates the extent of an employee's uncertainty about appropriate actions for one's job [22]. For example, role ambiguity can result when an employee is not clear about having the authority to make decisions or about job performance expectations. Due to uncertain role expectations, employees might hesitate to make decisions and meet expectations through trial and error [23].

\subsection{Workload}

The amount of work is considered to directly reduce the amount of time available for non-work activities in terms of time-based strains. In addition, work demands such as weekly work hours and workload influence role balance [24]. Further, in a study on physician experience, greater scheduling flexibility at work was found to be positively associated with well-being [25]. In human resource practices, effective work scheduling is a proven solution for balancing work and family activities, as well as reducing stress [26].

Workload includes aspects such as how often one's job requires faster work and how often one's job interferes with one's family life [13].

\subsection{WS in the Hospitality Industry}

The working environment of the hospitality industry is characterized by irregular and long working hours, role pressure and work overload. Therefore, hospitality employees facing such stressors may easily become nervous and anxious, in turn leading to dissatisfaction and negative emotions towards work [27].

Extant research in this respect revealed that employee stress in the hospitality industry is a pertinent issue, as exhausted and cynical workers can negatively affect service delivery; that is, less stressed employees provide better customer service than more stressed ones [28]. Therefore, working in the hospitality industry can be stressful, further reinforced by poor working conditions and low wages [5].

In general, work-related stress has been shown to cause a decline in job performance [29], increase in fatigue, more depressive symptoms and hostility [30]. In addition, the literature also emphasizes that employees in the hotel industry experience greater WS due to constant interaction with both associates and guests [28]. In fact, Pavesic and Brymer [31] state that young and qualified employees in the hospitality industry quit because of the long working hours, low 
wages, inflexible work schedule and stress caused by workload.

It could be concluded that stress in the hospitality industry may result in decreased productivity and increased healthcare costs for the employer [27].

In a study on WS in relation to personal characteristics, Bahar (2006) revealed that such variables as marital status, age and educational status did not vary in any dimension of WS, despite finding significant correlations between factors such as gender, having or not having children and the position. However, O’Neill and Davis [27] showed an insignificant difference between stress and individual attributes such as gender and marital status.

In terms of gender-specific stressors, the literature reveals higher levels of occupational stress in female employees with different interpretations and coping strategies [32]. In addition, Fotinatos-Ventouratos and Cooper [33] found that female managers experience considerable pressure compared to their male counterparts.

Nevertheless, studies on this aspect of the hospitality industry are limited, including the nature, quantity and outcomes of stress among employees. Within the hospitality industry, WS is considered one of the most important issues faced by managers because it affects the performance of employees at all levels, including managers (Ross, 1995). In Taiwan, WS has been scarcely studied, particularly in the hospitality industry, and its determinants in relation to varied employee demographics. Thus, in addition to elucidating the concept of occupational stress, the main objectives of this study were as follows: 1) to measure job stress levels among different categories of employees in Taiwanese hotels; and 2) to analyze job stress in Taiwan based on individual differences (job level, gender and marital status).

Therefore, the present study aimed to investigate the common work stressors among Taiwanese employees at five-star hotels, and the extent of their occurrence. Further, this study develops and tests hypotheses for examining any significant differences in the frequency of work stressors by job level, gender and marital status.

\subsection{Hypotheses Development}

Recent studies have shown a more negative correlation between stress and job performance among managers than non-managers [29] [34]. Although these differences in stress among managers and employees have not been analyzed empirically, hotel managers are expected to perceive higher degrees of stress than would front-line employees due to their high levels of responsibility and long working hours. There-fore, the following hypothesis is postulated:

Hypothesis 1. Hotel managers will report a greater occurrence of daily work stressors than front-line employees will.

Other studies indicated gender disparity in the perceived job stress, with women generally experiencing greater work stress [10] [16] than men. As former research has not experimentally analyzed the level of stress experienced by males 
versus females, the following hypothesis is suggested:

Hypothesis 2. Women will report a greater occurrence of work stressors than men will.

Previous studies suggested that married employees tend to experience different levels of stress from single employees [35]. However, these studies did not experimentally determine the levels of stress in married versus unmarried employees. Therefore, the following hypothesis is made:

Hypothesis 3. Married employees will report greater daily work stressors than unmarried employees do.

The present study aimed to investigate the common work stressors and their extent among Taiwanese employees at five-star hotels. Further, this study develops and tests hypotheses for examining any significant differences in the frequency of work stressors by job level, gender and marital status.

\section{Methodology}

\subsection{Participants and Procedures}

In this study, the researcher focused on Taiwanese five-star hotels due to the numerous managers and hourly workers employed. These hotels also aim to provide excellent service; invest in people by considering the vital role of internal customers in providing customer excellence service; and consider the skilled workforce as one of the most important assets of an enterprise.

Taiwan has a total of 61 five-star hotels. The participants for this study were recruited from 40 five-star hotels located in Taiwan. Therefore, these 40 hotels were used to capture the variability for interpreting the results and providing more external validity to the results. The study incorporated almost all hotel departments, which can appropriately represent all job classifications and characteristics of the target population's organizational roles for research purposes.

Front-line employees were chosen as they are most visible to guests and play a key role in providing excellent service. Moreover, front-line employees interact with hotel guests daily to fulfil various requests from customers. Again, front-line jobs in hotels primarily involve face-to-face contact with guests. This real-time nature of service delivery indicates that workers in this environment are under pressure to respond promptly.

The researcher contacted the managements of the 40 hotels mentioned to explain the aim of the study and obtain permission for data collection. Based on the information provided by the hotel managements, the total number of frontline employees was 6050 and managers 1971. A simple random sample was used for the participants as the population is homogeneous, with each individual having the same probability of being selected. A sample of 605 and 197 individuals with a percentage of 10 is acceptable [36]. Self-administered questionnaires distributed by the researcher to the hotel employees were filled using paper and pencil. A total of 400 and 140 questionnaires were retrieved from front-line employees 
and managers, respectively, yielding a response rate of $68 \%$ and $66 \%$.

\subsection{Measures}

The survey instrument was designed based on the literature. This instrument was tested with a pilot sample of 40 managers and front-line employees (20 for each sample). No changes were made to the instrument as because the employees did not have any difficulty in understanding the items of the pilot test.

The survey consisted of two parts. The first incorporated demographic information (gender, age, marital status and job level). This section was used to further examine the employee's work stressors in relation to the job level, gender and marital status.

The second part consisted of four WS categories: Role Conflict, Role Ambiguity, Workload and Interpersonal Conflict. Each category in turn included sub-items to assess the presence and frequency of work as well as the most common perceived WS by Taiwanese hotel employees.

In previous studies, Spector [13] and Spector and O'Connell [18] specifically developed measures with the strongest reliability and validity at the time, based on which this study's instrument was designed.

Role conflict and role ambiguity were measured using two subscales developed by Rizzo et al. [23]. The role conflict subscale comprised eight items, measured on a 5-point Likert-type scale from 1 indicating "never" to 5 denoting "always." The subscale included the following items: I have to break a rule or policy in order to carry out an assignment, I have to do things that should be done differently under different conditions and I receive an assignment without the manpower to complete it.

The six-item role ambiguity subscale was measured on the scale noted earlier. This includes the following items: I have clear, planned goals and objectives for my job and I clearly know what my responsibilities are.

A workload stressor subscale included five items, also measured on the abovementioned 5-point Likert scale, for measuring workload. It includes the following items: how often does your job require you to work very fast and how often you do more work than you can do well [13].

Spector's [13] four-item subscale, measured on a five-point Likert-type scale ranging from "never" to "always", was used to assess interpersonal conflict. It includes the following items: how often do other people do nasty things to you at work and how often do you get into arguments with others at work.

Internal reliability was assessed by calculating "Cronbach's alpha”. An $\alpha$-value of 0.82 was obtained, which is considered an acceptable level of internal reliability. The coefficient of stability of the instrument was calculated using the "Spearman correlation coefficient" formula. The items showed positive correlations ( $r$ $=0.85$ ), indicating the reliability of the instrument. These results indicated a high correlation between the factors and the variables as well as acceptable convergent and discriminate validity [37]. 


\subsection{Statistical Analyses}

The data were collected and analyzed using Statistical Package for Social Sciences (SPSS/version 20) software. The arithmetic mean, standard deviation and chisquared test were used for categorized parameters, whereas a numerical data $t$-test was used to test the relationship between employees and managers and their perceived level of WS. In addition, an analysis of variance (ANOVA) test was used to explore the difference between more than two groups, for example, in the demographic characteristics (marital status). After the ANOVA test, the Duncan method was used to determine the difference between groups. Finally, to determine the correlation between two variables, the Spearman correlation co-efficient test was used to indicate the level of significance.

\section{Results}

The primary aim of this study is to elucidate the common work stressors among Taiwanese front-line employees and managers in five-star hotels. Table 1 provides this information. The mean gap scores were used to indicate the incidence of most common work stressors. Managers reported "role conflict" as a major work stressor with a mean score of $M=3.98$. This included working with more than one section/department that operate differently, receiving incompatible requests of equal importance from two or more people and doing things that should be done differently under different conditions, with a mean score of 3.93, 3.83 and 3.72, respectively. The second most common stressor among managers was role ambiguity $(M=3.8)$ such as "Things are so clear that I am able to divide my time properly between various activities at work" with a low mean score of 2.47 .

These findings are supported by a recent study by Ryan et al. [34], who confirmed role conflict and role ambiguity as significant predictors of WS.

The third most common stressor was workload with a total mean score of $M=$ 3.8 , specifically excessive workload that cannot be finished during working hours $(M=4.25)$.

Table 1. Work stressors experienced by managers $(N=140)$ against front-line employees $(N=400)$.

\begin{tabular}{|c|c|c|c|c|c|}
\hline Stressors & Job level & $\mu$ & $\sigma$ & $t$ & $p$ \\
\hline \multirow{3}{*}{ Role conflict } & Employees & 3.653 & 0.489 & \multirow{3}{*}{7.25} & \multirow{3}{*}{$0.001^{*}$} \\
\hline & & & & & \\
\hline & Managers & 3.981 & 0.517 & & \\
\hline \multirow[b]{2}{*}{ Role ambiguity } & Employees & 3.767 & 0.577 & \multirow[b]{2}{*}{8.45} & \multirow[b]{2}{*}{$0.004^{*}$} \\
\hline & Managers & 3.841 & 0.657 & & \\
\hline \multirow{3}{*}{ Workload } & Employees & 3.723 & 0.708 & \multirow{3}{*}{9.7} & \multirow{3}{*}{$0.0001^{\star}$} \\
\hline & & & & & \\
\hline & Managers & 3.822 & 0.529 & & \\
\hline \multirow{2}{*}{ Interpersonal conflict } & Employees & 3.196 & 0.905 & \multirow{2}{*}{0.786} & \multirow{2}{*}{0.376} \\
\hline & Managers & 3.233 & 0.547 & & \\
\hline
\end{tabular}


Like managers, the most common stressors experienced by front-line employees were as follows: role conflict $(M=3.6)$, such as receiving an assignment without adequate resources and materials for execution $(M=3.86)$; role ambiguity $(M=3.76)$, such as "I clearly know what my responsibilities are" $(M=3.88)$; and workload $(M=3.72)$, such as "having too heavy workload that you cannot possibly finish during working hours" $(M=3.52)$.

Surprisingly, neither managers $(M=3.2)$ nor employees $(M=3.1)$ perceived "interpersonal conflict" as a significant work stressor. This finding was not supported by past studies, which revealed that individuals face various types of stressors every day, with interpersonal conflict being the most common, as well as work overload and arguments at work and at home [32].

O’Neill and Davis [27] revealed that hotel managers most commonly experienced interpersonal conflict, such as trying to avoid an argument. Due to greater pressure at work, Taiwanese employees may not pay attention to others while working. Moreover, Egyptian employees may enjoy a good work relationship with their colleagues.

Therefore, the most common stressors found among managers and front-line employees, role conflict and role ambiguity, have certain individual, organizational and managerial implications for business practice.

These practices could be as follows: Hotel managers must provide employees with the sufficient materials to execute their job efficiently, ensuring that every employee knows clearly his job responsibility and helping them avoid unnecessary time constraints.

\section{Test of Hypotheses}

The results of the hypothesized relationships are presented in Table 2 and Table 3.

\section{1) Hypothesis 1}

H1. Hotel managers will report a greater occurrence of daily work stressors than front-line employees will.

Hypothesis 1 predicted that hotel managers will experience greater WS on a daily basis than other front-line employees.

This hypothesis was developed to determine whether work stressors can be differently perceived with job level, the second objective of this study. The t-test was used to test the hypothesis and to examine any significant differences between the various groups. Table 1 shows that hotel managers highly and significantly perceived almost all the categories of work stressors more frequently than front-line employees did, specifically role conflict $(p<0.001)$, role ambiguity $(p$ $<0.004)$ and workload $(p<0.0001)$.

This may be caused by the higher level of responsibilities and longer working hours for managers than for than front-line employees. Thus, managerial stress should be addressed by practitioners in the hospitality industry through certain measures, as this can result in additional costs for the hotel enterprise. 
Table 2. Work stressors experienced by males $(N=403)$ versus females $(N=137)$.

\begin{tabular}{|c|c|c|c|c|c|}
\hline Stressors & Gender & $\mu$ & $\sigma$ & t-test & $p$ \\
\hline \multirow{2}{*}{ Role conflict } & Male & 3.4256 & 0.50553 & \multirow{2}{*}{19.664} & \multirow{2}{*}{$0.0001^{\star}$} \\
\hline & Female & 2.9927 & 0.35348 & & \\
\hline \multirow{2}{*}{ Role ambiguity } & Male & 3.4035 & 0.63411 & \multirow{2}{*}{0.207} & \multirow{2}{*}{0.649} \\
\hline & Female & 3.4307 & 0.49699 & & \\
\hline \multirow{2}{*}{ Workload } & Male & 3.4612 & 0.64025 & \multirow{2}{*}{2.01} & \multirow{2}{*}{$0.05^{*}$} \\
\hline & Female & 3.5985 & 0.92720 & & \\
\hline \multirow{2}{*}{ Interpersonal conflict } & Male & 3.5865 & 0.84289 & \multirow{2}{*}{1.64} & \multirow{2}{*}{0.109} \\
\hline & Female & 3.6934 & 0.79115 & & \\
\hline Stressors & Marital Status & $\mu$ & $\sigma$ & $F$ & $p$ \\
\hline \multirow{4}{*}{ Role conflict } & Single & 3.384 & 0.488 & \multirow{4}{*}{3.625} & \multirow{4}{*}{$0.013^{*}$} \\
\hline & Married & 3.354 & 0.488 & & \\
\hline & Widowed & 3.262 & 0.681 & & \\
\hline & Divorced & 3.195 & 0.440 & & \\
\hline \multirow{4}{*}{ Role ambiguity } & Single & 3.360 & 0.482 & \multirow{4}{*}{26.3} & \multirow{4}{*}{$0.0001^{\star}$} \\
\hline & Married & 3.262 & 0.669 & & \\
\hline & Widowed & 3.967 & 0.180 & & \\
\hline & Divorced & 3.478 & 0.536 & & \\
\hline \multirow{4}{*}{ Workload } & Single & 3.752 & 0.434 & \multirow{4}{*}{26.2} & \multirow{4}{*}{$0.0001^{\star}$} \\
\hline & Married & 3.532 & 0.564 & & \\
\hline & Widowed & 2.820 & 0.958 & & \\
\hline & Divorced & 3.504 & 0.908 & & \\
\hline \multirow{4}{*}{ Interpersonal conflict } & Single & 3.688 & 0.530 & \multirow{4}{*}{0.712} & \multirow{4}{*}{0.545} \\
\hline & Married & 3.595 & 0.648 & & \\
\hline & Widowed & 3.508 & 1.286 & & \\
\hline & Divorced & 3.628 & 1.095 & & \\
\hline
\end{tabular}

Duncan method: The similar small letters indicate the insignificance, and the different letters indicate the significance.

Table 3. The correlation between work stressors as perceived by managers and employees.

\begin{tabular}{|c|c|c|c|c|c|}
\hline Stressors & & Role Conflict & $\begin{array}{c}\text { Role } \\
\text { Ambiguity }\end{array}$ & Workload & $\begin{array}{c}\text { Interpersonal } \\
\text { Conflict }\end{array}$ \\
\hline \multirow{2}{*}{ Role conflict } & Pearson correlation & 1 & $0.250^{\star *}$ & $0.383^{\star *}$ & $0.283^{\star *}$ \\
\hline & Sig. (2-tailed) & & 0.000 & 0.000 & 0.000 \\
\hline \multirow{2}{*}{ Role Ambiguity } & Pearson correlation & $0.250^{\star *}$ & 1 & $0.189^{\star *}$ & 0.032 \\
\hline & Sig. (2-tailed) & 0.000 & & 0.000 & 0.460 \\
\hline \multirow{2}{*}{ Workload } & Pearson correlation & $0.383^{\star *}$ & $0.189^{* *}$ & 1 & $0.384^{\star *}$ \\
\hline & Sig. (2-tailed) & 0.000 & 0.000 & & 0.000 \\
\hline \multirow{2}{*}{$\begin{array}{c}\text { Interpersonal } \\
\text { Conflict }\end{array}$} & Pearson correlation & $0.283^{\star *}$ & 0.032 & $0.384^{\star *}$ & 1 \\
\hline & Sig. (2-tailed) & 0.000 & 0.460 & 0.000 & \\
\hline
\end{tabular}


Therefore, the first hypothesis (hotel managers will report a greater occurrence of daily work stressors than front-line employees) is supported, and consequently the second study objective was achieved.

\section{2) Hypothesis 2}

H2. Women will report a greater occurrence of work stressors than men will.

This hypothesis proposes that women generally experience higher WS than men do.

The second hypothesis was developed to examine the differences of work stressors by gender, the third objective of this study. The study reported a highly significant difference of work stressors based on gender. As shown in Table 2, the $t$-test indicated a highly significant difference in the perceived work stressors between male and female employees. Women experienced more stressors than males did in each stressor category, specifically role conflict $(p<0.0001)$, workload $(p<0.038)$, interpersonal conflict $(p<0.04)$ and role ambiguity $(p<0.022)$. A similar was obtained by Almeida and Kessler [32], Tsaur and Tang [38], and Zarra-Nezhad, Moazami-Goodarzi, Hasannejad, and Roushani [39], who concluded that, despite the increasing career opportunities, women still face challenges at the workplace as well as want fundamental changes in their family adaptability and cohesion, WS and economic status. In a recent study, O'Neill and Davis [27] showed no significant difference based on gender, although this does not necessarily indicate the absence of such differences in the hotel industry in general.

This finding is explained by the woman's important role in a family, resulting in uncertainty over the unstable sector, attitudes of managers, busy schedules and the social role of being a woman.

Consequently, employers need to allot time for entertainment and relaxation in a bid to reduce WS. Moreover, female employees should be encouraged to manage and plan their time to successfully eliminate or reduce WS. Married female employees require a flexible rotating shift that can help them control work stressors.

Based on the above-mentioned findings, the second hypothesis is supported and the third study objective achieved.

\section{3) Hypothesis 3}

H3. Married employees will report greater daily work stressors than unmarried employees.

This hypothesis suggested that married employees tend to experience different levels of stress from single employees.

The third hypothesis was proposed to examine the differences of work stressors by marital status, the fourth objective of this study. The ANOVA test was used to determine the relationship between the work stressors and the four characteristics within marital status (married, widowed, divorced and single). Then the Duncan method was used to determine the between-group difference. As shown in Table 3, married Taiwanese employees faced more work stressors than do unmarried employees, specifically role conflict $(p<0.013)$, role ambiguity $(p$ 
$<0.0001)$ and workload $(p<0.0001)$. This finding has been confirmed in past studies by Almeida and Kessler [32] and Thoits [35].

In a recent study, O’Neill and Davis [27] indicated no significant difference based on marital status; however, this result does not necessarily indicate the absence of such differences in the hotel industry.

Based on the above-mentioned results, the third hypothesis is sustained.

Finally, a significant correlation among the four aspects of work stress as experienced by Taiwanese employees was reported, indicating that each type of work stressors significantly correlated with the others (Table 3). As shown in Table 3, when an employee experiences one stressor, he or she faces the other stressors as well; all experienced aspects of stressors were found to be significantly correlated among managers and front-line employees.

For example, role conflict and role ambiguity were found to be significantly correlated $(r=0.250)$, which indicated that one role conflict stressor is accompanied by a consequent role ambiguity. Another significant correlation could be noticed between workload and role ambiguity $(r=0.189)$.

\section{Conclusions and Implications}

This study is the first to investigate the issue of WS among employees in Taiwanese five-star hotels. As hotel employees play an important role in providing excellent guest service, their job stress levels are a pertinent issue.

The first objective of the study is to explore the common work stressors among Taiwanese front-line employees and managers at five-star hotels. This study revealed that role conflict and role ambiguity are the major causes of WS; therefore, the top management must instate some practices to reduce or eliminate these stressors.

Firstly, role conflict can be overcome by the following practices: providing the employees with sufficient materials for efficient job performance, ensuring that every employee is clear about his or her job responsibility, revising each employee's job description and helping them avoid unnecessary time constraints.

In addition, the top management can organize specific work-shops and seminars for employees as a platform for discussing problems due to role conflict.

Secondly, as role ambiguity was found to be a common work stressor among Taiwanese hotel employees, the top management must create a professional work environment with clear role expectations and specific responsibilities to ensure clarity. This environment can be introduced through training programs for hotel employees in problem-solving, time management and communication skills, to minimize problems due to role ambiguity.

Thirdly, hospitality practitioners must also ensure that employees are motivated and productive through a diversity of experiences, and not overwhelmed. Therefore, employers must use part-time employees to reduce workloads and prevent job interference with family life.

Fourthly, this study revealed significant differences in WS by gender, job level 
and marital status. The study reported higher experienced work stressors for managers than for front-line employees.

Therefore, the top management can decrease WS in the hotel industry by paying attention to each member of the staff and address their problems through their approaches. Moreover, the managers' problems can also be addressed in such practices. These practices will provide more career opportunities as well as impart dignity to one's job.

Fifthly, the study reported a highly significant difference of work stressors in relation to gender. Women experienced more stressors than men did; consequently, hospitality employers must allot a flexible time slot for entertainment and relaxation for female employees to reduce WS. Moreover, female employees should be encouraged to manage and plan their time to successfully eliminate or reduce WS.

Furthermore, the other implications for business practices are as follows: developing the HRM-based policies (flexible work hours, on-site childcare, emergency childcare services, holiday and vacation care programmers and sick childcare) and also creating a supportive work environment that will reduce work family conflict among married employees, especially for women.

The study revealed that married Egyptian employees perceived and experienced more work stressors than did unmarried employees. Therefore, married employees, especially women, need a flexible rotating shift to help cope with work stressors and balance work family issues.

Finally, other general practices for reducing or eliminating WS in the hospitality industry are as follows: choosing employees who can handle stress better through a planned interview, as well as training them to handle WS through stress management seminars or workshops. In turn, employers can recruit employees who function optimally even in stressful situations, which would help lower the costs associated with stress management for employees.

\section{Conflicts of Interest}

The author declares no conflicts of interest regarding the publication of this paper.

\section{References}

[1] Chiang, F.F.T., Birtch, T.A. and Kwan, H.K. (2010) The Moderating Roles of Job Control and Work-Life Balance Practices on Employee Stress in the Hotel and Catering Industry. International Journal of Hospitality Management, 29, 25-32. https://doi.org/10.1016/j.ijhm.2009.04.005

[2] Namasivayam, K. and Hinkin, T. (2003) The Customer's Role in the Service Encounter: The Effects of Control and Fairness. Cornell Hotel \& Restaurant Administration Quarterly, 44, 26-36. https://doi.org/10.1177/001088040304400303

[3] Siu, O. (2003) Job Stress and Job Performance among Employees in Hong Kong: The Role of Chinese Works Values and Organizational Commitment. International Journal of Psychology, 38, 337-347. https://doi.org/10.1080/00207590344000024 
[4] Ivancevich, J.M., Matteson, M.T. and Preston, C. (1982) Occupational Stress, Type A Behavior, and Physical Well Being. Academy of Management Journal, 25, 373-391. https://doi.org/10.2307/255998

[5] Lo, K. and Lamm, F. (2005) Occupational Stress in the Hospitality Industry: An Employment Relations Perspective: New Zealand. Journal of Employment Relations, 30, 22-48.

[6] Jamal, M. (1990) Relationship of Job Stress and Type-A Behavior to Employees' Job Satisfaction, Organizational Commitment, Psychosomatic Health Problems, and Turnover Motivation. Human Relations, 43, 727-738. https://doi.org/10.1177/001872679004300802

[7] Erkutlu, H.V. and Chafra, J. (2006) Relationship between Leadership Power Base and Job Stress of Subordinates: Example from Boutique Hotels. Management Research News, 29, 285-297. https://doi.org/10.1108/01409170610674419

[8] Holmlund-Rytkonen, M. and Strandvik, T. (2005) Stress in Business Relationships. Journal of Business \& Industrial Marketing, 20, 12-22. https://doi.org/10.1108/08858620510576757

[9] Lu, L., Cooper, C.L., Kao, S.-F. and Zhou, Y. (2003) Work Stress, Control Beliefs and Well-Being in Greater China: An Exploration of Sub-Cultural Differences between the PRC and Taiwan. Journal of Managerial Psychology, 18, 479-510. https://doi.org/10.1108/02683940310494359

[10] Antoniou, A.-S., Polychroni, F. and Vlachakis, A.-N. (2006) Gender and Age Differences in Occupational Stress and Professional Burnout between Primary and High-School Teachers in Greece. Journal of Managerial Psychology, 21, 682-690. https://doi.org/10.1108/02683940610690213

[11] Chen, P.Y. and Spector, P.E. (1991) Negative Affectivity as the Underlying Cause of Correlations between Stressors and Strains. Journal of Applied Psychology, 76, 398-407. https://doi.org/10.1037/0021-9010.76.3.398

[12] Kahn, R.L., Wolfe, D.M., Quinn, R.P., Snoek, J.D. and Rosenthal, R.A. (1964) Organizational Stress: Studies in Role Conflict and Ambiguity. Wiley, New York.

[13] Spector, P.E. (1987) Interactive Effects of Perceived Control and Job Stressors on Affective Reactions and Health Outcomes for Clerical Workers. Work and Stress, 1, 155-162. https://doi.org/10.1080/02678378708258497

[14] Soltani, I., Hajatpour, S., Khorram, J. and Nejati, M.H. (2013) Investigating the Effect of Role Conflict and Role Ambiguity on Employees' Job Stress: Articulating the Role of Work-Family Conflict. Management Science Letters, 3, 1927-1936. https://doi.org/10.5267/j.msl.2013.06.036

[15] Harris, E.G., Artis, A.B., Walters, J.H. and Licata, J.W. (2006) Role Stressors, Service Worker Job Resourcefulness, and Job Outcomes: An Empirical Analysis. Journal of Business Research, 59, 407-415. https://doi.org/10.1016/j.jbusres.2005.06.003

[16] Michael, G., Anastasios, S., Helen, K., Catherine, K. and Christine, K. (2009) Gender Differences in Experiencing Occupational Stress: The Role of Age, Education, and Marital Status. Stress and Health, 25, 397-404. https://doi.org/10.1002/smi.1248

[17] Spector, P.E. (1997) Job Satisfaction: Application, Assessment, Cause, and Consequences. Sage Publications, Thousand Oaks. https://doi.org/10.4135/9781452231549

[18] Spector, P.E. and O'Connell, B.J. (1994) The Contribution of Individual Dispositions to the Subsequent Perceptions of Job Stressors and Job Strains. Journal of Occupational and Organizational Psychology, 67, 1-11. https://doi.org/10.1111/j.2044-8325.1994.tb00545.x 
[19] Sampson, W.G. and Akyeampong, O. (2014) Work-Related Stress in Hotels: An Analysis of the Causes and Effects among Frontline Hotel Employees in the Kumasi Metropolis, Ghana. Journal of Tourism and Hospitality, 3, 3-9. https://doi.org/10.4172/2167-0269.1000127

[20] Barnett, R.C. and Hyde, J.S. (2001) Women, Men, Work, and Family: An Expansionist Theory. American Psychologist, 56, 781-796.

https://doi.org/10.1037/0003-066X.56.10.781

[21] Bekker, M.H.J., de Jong, P.F., Zijestra, F.R.H. and van Landeghem, P. (2000) Combining Care and Work: Health and Stress Effects in Male and Female Academics. Journal of Behavioral Medicine, 7, 28-43. https://doi.org/10.1207/S15327558IJBM0701_3

[22] Miles, R.H. (1976) Role Requirements as Sources of Organizational Stress. Journal of Applied Psychology, 61, 172-179. https://doi.org/10.1037/0021-9010.61.2.172

[23] Rizzo, J.R., House, R.J. and Lirtzman, S.I. (1970) Role Conflict and Ambiguity in Complex Organizations. Administrative Science Quarterly, 15, 150-163. https://doi.org/10.2307/2391486

[24] Milkie, M.A. and Peltola, P. (1999) Playing All the Roles: Gender and the Work Family Balancing Act. Journal of Marriage and Family, 61, 476-490.

https://doi.org/10.2307/353763

[25] Hecht, L.M. (2001) Role Conflict and Role Overload: Different Concepts, Different Consequences. Sociological Inquiry, 71, 111-121. https://doi.org/10.1111/j.1475-682X.2001.tb00930.x

[26] Facer, R.L. and Wadsworth, L. (2008) Alternative Work Schedules and Work Family Balance: A Research Note. Review of Public Personnel Administration, 28, 166-177. https://doi.org/10.1177/0734371X08315138

[27] O’Neill, J. and Davis, K. (2011) Work Stress and Well-Being in the Hotel Industry. International Journal of Hospitality Management, 30, 385-390. https://doi.org/10.1016/j.ijhm.2010.07.007

[28] Kim, H.J., Shin, K.H. and Umbreit, W.T. (2007) Hotel Job Burnout: The Role of Personality Characteristics. International Journal of Hospitality Management, 26, 421-434. https://doi.org/10.1016/j.ijhm.2006.03.006

[29] Gilboa, S., Shirom, A., Fried, Y. and Cooper, C. (2008) A Meta-Analysis of Work Demand Stressors and Job Performance: Examining Main and Moderating Effects. Personnel Psychology, 61, 227-272. https://doi.org/10.1111/j.1744-6570.2008.00113.x

[30] Lepine, J.A., Lepine, M.A. and Jackson, C.L. (2004) Challenge and Hindrance Stress: Living with Exhaustion, Motivation to Learn, and Learning Performance. Journal of Applied Psychology, 89, 883-895. https://doi.org/10.1037/0021-9010.89.5.883

[31] Pavesic, D.V. and Brymer, R.A. (1990) Job Satisfaction: What's Happening to the Young Manager. Cornell Hotel and Restaurant Administration Quarterly, 30, 90-96. https://doi.org/10.1177/001088049003000420

[32] Almeida, D.M. and Kessler, R.C. (1998) Everyday Stressors and Gender Differences in Daily Distress. Journal of Personality and Social Psychology, 75, 670-680. https://doi.org/10.1037/0022-3514.75.3.670

[33] Fotinatos-Ventouratos, R. and Cooper, C. (2005) The Role of Gender and Social Class in Work Stress. Journal of Managerial Psychology, 20, 14-23. https://doi.org/10.1108/02683940510571612

[34] Ryan, B., Ma, E., Hsiao, A. and Ku, M. (2015) The Work-Family Conflict of Univer- 
sity Foodservice Managers: An Exploratory Study of Its Antecedents and Consequences. Journal of Hospitality and Tourism Management, 22, 10-18.

https://doi.org/10.1016/j.jhtm.2014.12.005

[35] Thoits, P.A. (1987) Gender and Marital Status Differences in Control and Distress: Common Stress versus Unique Stress Explanations. Journal of Health and Social Behavior, 28, 7-22. https://doi.org/10.2307/2137137

[36] Gay, L.R. and Diehl, P.L. (1992) Research Methods for Business and Management. Maxwell Macmillan International, New York.

[37] Churchill, G.A. and Iacobucci, D. (2005) Marketing Research: Methodological Foundations. 9th Edition, Thomson/South-Western, Cincinnati.

[38] Tsaur, S.H. and Tang, Y. (2012) Job Stress and Well-Being of Female Employees in Hospitality; the Role or Regulatory Leisure Coping Style. International Journal of Hospitality Management, 31, 1038-1044. https://doi.org/10.1016/j.ijhm.2011.12.009

[39] Zarra-Nezhad, M., Moazami-Goodarzi, A., Hasannejad, L. and Roushani, K. (2010) Occupational Stress and Family Difficulties of Working Women. Current Research in Psychology, 1, 75-81. https://doi.org/10.3844/crpsp.2010.75.81 